\title{
Toxic chemical exposure from global fish trade
}

\author{
The global trade of fish and fish products brings with it the challenge of identifying exposure to contaminants from \\ imported products. Marine fish trade models can now quantify human exposure to persistent organic pollutants.
}

\author{
Derek C. G. Muir
}

an the $\mathrm{n}$ the past 50 years, marine fishery catches and the expansion of aquaculture have contributed to global fish consumption exceeding that of meat ${ }^{1}$. International exports of fish and fish products rose from US $\$ 8$ billion in 1976 to US $\$ 143$ billion in $2016^{1,2}$. Along with this increased trade come concerns about transferring contaminants globally via food exports and imports rather than via long-range transport in the atmosphere or in ocean currents, and subsequent contamination of local/regional food webs ${ }^{3-5}$. The sources of contaminants can thus be far removed geographically and possibly result in more elevated dietary exposures than from local products. This is particularly a concern for some marine fish products where bioaccumulative contaminants such as polychlorinated biphenyls (PCBs) and mercury may be elevated in species such as herring, Atlantic cod and tuna ${ }^{5}$ or in fish-meal-based diets for mariculture ${ }^{6}$. Widely used in electrical transformers and building products until banned in the 1970s and 1980s, PCBs are among the best characterized of the much larger group of persistent organic pollutants (POPs) with respect to physicochemical properties and emission estimates. Despite national bans, as well as globally under the Stockholm Convention, PCBs remain elevated in marine fish, especially in coastal areas of Western Europe and eastern USA. Fish farmed in seawater mariculture systems and fed wild-caught fish-meal are also exposed to PCBs and other POPs from multiple sources ${ }^{6}$. The increasing complexity of fish production and global trade makes it challenging to quantify the toxic chemical exposure that consumers face from eating fish. Writing in Nature Food, Huang and colleagues set out to quantify fish consumer POP exposure as a result of international fish trade ${ }^{7}$.

Huang and colleagues selected PCB-153, a hexachlorobiphenyl, as representative of the PCB class, due to its resistance to biodegradation and to the availability of extensive monitoring data on humans and wildlife exposure. However, PCB-153 has only been widely measured in marine fish in Western Europe and in East Asia (Japan, Korea, China), so a straightforward approach of using global monitoring data for marine fish could not be applied. Therefore, Huang and colleagues used chemical fate and bioaccumulation models to estimate concentrations of PCB-153 in marine fish globally. First, they utilized global PCB emission data ${ }^{8}$ and an existing POP global-scale atmospheric transport model $^{9}$ to estimate PCB-153 concentrations in air, water and sediment. Next, POP concentrations in 38 species of coastal marine fish were estimated based on water and sediment results using a food web bioaccumulation model ${ }^{10}$. Country-level information was estimated from the Sea Around Us database and condensed into seven broad categories - anchovies, herring-like, cod-like, flatfish, salmon, tuna and billfish, and all other fish. Finally, a PCB-153 estimated daily intake (EDI) was calculated for each fish category based on per capita consumption in each country (from the UN Comtrade and FAO fishery statistics websites). Validating the model was difficult due to poor data availability, but modelled and measured concentrations in air, water and sediments agreed reasonably well, typically within less than one order of magnitude.

Huang and colleagues showed that $84 \%$ of PCB exposure in sub-Saharan fish consumers could be attributed to fish imported from Western and Northern Europe, compared with $<2 \%$ from local fish. In contrast, European fish consumers had reduced exposure due to consumption of fish imported from countries fishing in regions with low PCB-153 contamination. The estimated PCB-153 EDI from Atlantic salmon trade was included by the authors as a case study, showing that PCB-153 accumulation in wild-caught and farmed salmon could be estimated within a factor of two of measured concentrations. PCB153 EDIs based on consumption of salmon raised with plant-based feeds were much lower compared with that of salmon fed with traditional fish-based feed.
Huang and colleagues generated a useful tool to estimate - on a per country basis - exposure to specific chemicals from the global trade of marine fish and fish products, and to examine temporal trends following bans or phase-outs of bioaccumulative chemicals. In principle, the modelling approach could be expanded to freshwater aquaculture and coastal crustacean fisheries, for which international trade data are also available. The intake of nutritionally beneficial substances, such as the long-chain omega- 3 fatty acids from fishery sources, may also be estimated using the same approach. With the ongoing growth of aquaculture and increasing use of fish as a dietary protein source, this information may prove valuable to the fishing and aquaculture industries, non-government and government stakeholders, policy makers and trade-related agencies.

\section{Derek C. G. Muir (D)}

Environment and Climate Change Canada, Burlington, Ontario, Canada.

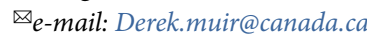

Published online: 11 May 2020

https://doi.org/10.1038/s43016-020-0080-3

\footnotetext{
References

1. FAO The State of World Fisheries and Aquaculture 2018: Meeting the Sustainable Development Goals (United Nations Food and Agriculture Organization, 2018).

2. UN 2018 International Trade Statistics Yearbook, Volume II, Trade by Product (United Nations, Department of Economic and Social Affairs, Statistics Division, 2019).

3. Ng, C. A. \& von Goetz, N. Environ. Health Perspect. 125, 1-7 (2017).

4. Lavoie, R. A., Bouffard, A., Maranger, R. \& Amyot, M. Sci. Rep. 8, 6705 (2018).

5. Undeman, E., Brown, T. N., McLachlan, M. S. \& Wania, F Environ. Res. Lett. 13, 064036 (2018)

6. Bell, J. G. et al. Aquaculture 324-325, 118-126 (2012).

7. Huang, T. et al. Nat. Food https://doi.org/10.1038/s43016-0200066-1 (2020).

8. Breivik, K., Armitage, J. M., Wania, F., Sweetman, A. J. \& Jones, K. C. Environ. Sci. Technol. 50, 798-805 (2016).

9. Ma, J., Daggupaty, S., Harner, T. \& Li, Y. Environ. Sci. Technol. 37, 3774-3781 (2003)

10. Gobas, F. A. P. C. Ecol. Model. 69, 1-17 (1993).
}

Competing interests

The author declares no competing interests. 